\section{(2) OPEN ACCESS}

\title{
Histopathological features of multiorgan percutaneous tissue core biopsy in patients with COVID-19
}

\author{
Xin-xin Wang $(1),{ }^{1}$ Chen Shao, ${ }^{1}$ Xiao-jie Huang, ${ }^{2}$ Lin Sun, ${ }^{1}$ Ling-jia Meng, ${ }^{1}$ Hui Liu, ${ }^{1}$ \\ Shi-jie Zhang, ${ }^{1}$ Hong-jun Li, ${ }^{3}$ Fu-dong Lv ${ }^{1}$
}

'Department of Pathology, Beijing Youan Hospital, Capital Medical University, Beijing, China

${ }^{2}$ Department of Infectious Disease, Beijing Youan Hospital, Capital Medical University, Beijing, China

${ }^{3}$ Department of Radiology, Beijing Youan Hospital, Capital Medical University, Beijing, China

\section{Correspondence to} Dr Fu-dong Lv, Department of Pathology, Beijing Youan Hospital, Capital Medical University, No.8 Xitoutiao Road, Youanmen outside, Fengtai District, Beijing 100069, China; Ifd@tom.com

Received 4 April 2020 Revised 5 July 2020

Accepted 16 July 2020 Published Online First 26 August 2020

\begin{abstract}
Aims The global outbreak of COVID-19 has resulted in an increased mortality. However, whether severe acute respiratory syndrome coronavirus 2 (SARS-CoV-2) can affect multiple organs is still unclear. In this study, postmortem percutaneous biopsies of multiple organs from deceased patients were performed to understand the histopathological changes caused by COVID-19. Methods Biopsy specimens of pulmonary, cardiac, hepatic and lymphoid tissues were obtained from three patients, who died due to COVID-19 pneumonia. H\&E stain, Masson trichrome stain, immunohistochemistry stain and in-situ hybridisation were used.
\end{abstract}

Results Pulmonary damages caused by SARS-CoV-2 infection was diffuse alveolar damage (DAD). In the early phase, the histological findings were mainly those of exudative features of DAD. The later phase was characterised by organisation of DAD combined with bacterial pneumonia. No serious damage was found in the bronchiolar epithelium and submucosal glands. The hepatic tissue revealed features of ischaemic necrosis, but findings suggestive of mild lobular hepatitis were also observed. The lymphoid tissue revealed features of non-specific acute lymphadenitis. The cardiac tissue revealed changes of underlying disease. SARS-CoV-2 RNAs were not detected in hepatocytes, cholangiocytes and lymphocytes of lymph nodes.

Conclusions COVID-19 predominantly involves the pulmonary tissue, causes DAD and aggravates the cardiovascular disease. However, other extrapulmonary tissues did not reveal any virus-specific findings, but were affected by multiple factors. The findings in this report caution the pathologists that they should not mistakenly attribute all the histological features to CoV infection. Moreover, the clinicians should pay attention to the potentially injurious and correctable causes.

\section{INTRODUCTION}

Since the isolation of the first human case infected by the coronavirus (CoV) in 1960s, seven strains of human CoVs have been reported. Among these seven strains, four are known to cause relatively mild diseases; however, remaining three strains (ie, severe acute respiratory syndrome $\mathrm{CoV}$ (SARS-CoV) and Middle East respiratory syndrome $\mathrm{CoV}$ (MERS-CoV), and SARS-CoV-2) can cause fatal outbreaks. Among these three strains, disease caused by the most recent strain, SARS-CoV-2, has reached a pandemic proportion and hundreds of thousands of patients with COVID-19 have died. ${ }^{1}$
Patients with severe COVID-19 can rapidly deteriorate into acute respiratory distress syndrome (ARDS), septic shock, metabolic acidosis, coagulation dysfunction that are difficult to treat and even progress to multiorgan failure. ${ }^{2}$ In order to understand the histopathological characteristics of the organs affected by SARS-CoV-2, we performed the postmortem organ biopsies on three patients who succumbed to COVID-19.

\section{MATERIALS AND METHODS Clinical history \\ Patient 1}

The patient was a 94-year-old woman, residing in Beijing and had a history of contact with a confirmed patients with COVID-19. She presented with a history of high-grade fever for the last 8 days and her throat swabs were found to be positive, twice, for SARS-CoV-2 nucleic acid. Thus, she was diagnosed as COVID-19 pneumonia, according to the 2020 China COVID-19 practice guidelines (fifth edition of the trial version). ${ }^{3}$ She also had a history of comorbidities such as hypertension, coronary heart disease (CHD), chronic cardiac insufficiency, pericardial effusion and gastro-oesophageal reflux disease. On the ninth day, after the onset of COVID-19 symptoms, she died of acute heart failure, acute coronary syndromes and other complications.

\section{Patient 2}

The patient was a 65 -year-old man, and 8 days ago, had travelled to Beijing from Wuhan, China. He had enjoyed good health till he presented with moderate fever that had begun 4 days prior to the confirmed diagnosis of COVID-19. Radiological examination of chest (CT) and laboratory investigations revealed bilateral pneumonia and a decreased peripheral lymphocyte count, respectively. Both the throat swabs were positive for SARS-CoV-2 nucleic acid. On the sixth day post admission, the patient required mechanical ventilation, due the development of respiratory distress and drop in oxygen saturation $\left(\mathrm{SaO}_{2}\right)$ to $64 \%$, despite being on oxygen inhalation $(10 \mathrm{~L} / \mathrm{min})$. Repeat chest CT revealed signs of aggravated pneumonia. On the seventh day, laboratory tests revealed an increase in the neutrophil count and procalcitonin (PCT) levels. On the eighth day, the condition of patient deteriorated rapidly, due to the onset of secondary bacterial pulmonary infection. The condition deteriorated 
further by the 12 th day, leading to renal insufficiency, sepsis, arrhythmia and multiorgan failure. The patient succumbed on the 16th day post admission (20th day after the onset of symptoms).

\section{Patient 3}

The patient was a 75-year-old woman, resident of Beijing, who was admitted to another hospital for chronic cardiac insufficiency, and had a history of exposure to COVID-19 positive patient. She had dry cough and problem of chest tightness on the sixth day following the exposure. Her throat swabs were positive, on two occasions, for SARS-CoV-2 nucleic acid. She had a history of hypertension, myocardial infarction (MI), CHD, type 2 diabetes mellitus and dyslipidaemia. Chest CT revealed multiple patchy shadows in both the lungs. Finally, a diagnosis of COVID-19 with acute exacerbation of chronic cardiac insufficiency was reached and she was transferred to our hospital for further management. During hospitalisation, the patient developed hypotension and arrhythmia. On the fourth day, laboratory tests revealed significant rise in the serum levels of creatine kinase and cardiac troponin-I. On the seventh day, there was a moderate increase in serum alanine aminotransferase and a mild increase in serum total bilirubin. On the 10th day post admission, the patient succumbed to multiorgan failure.

Clinical history of three cases is summarised in table 1.

\section{Tissue collection}

Percutaneous biopsies, using a 16 gauge needle, were performed bedside in all the three patients, within $60 \mathrm{~min}$, after they were pronounced dead. The biopsy of lung was performed in two patients (patients 1 and 2); however, an incidental biopsy of the intrathoracic lymph nodes was obtained in one of them (patient 2). Moreover, the biopsies of the heart and liver were performed in patient 3 . In this patient, a biopsy of kidney was also attempted, but was unsuccessful. In all three patients, the postmortem percutaneous needle biopsies were performed after obtaining the written and signed consent of the family members.

\section{Tissue processing, special stains, immunohistochemistry and in-situ hybridisation}

The tissues were subjected to routine processing procedures such as formalin fixation, paraffin embedding, slide sectioning and $\mathrm{H} \& \mathrm{E}$ staining. Masson trichrome and reticulin special stains were performed on hepatic and cardiac tissue. Immunohistochemical (IHC) staining was performed on lymphoid tissue, for lymphoid cell markers CD21, CD10, CD3, CD4 and CD8. Lymphocyte common antigen (LCA) was also performed on cardiac tissue. All immunoassays were performed according to the manufacturer's guidelines, using automated platform (Leica Bond-max, Germany). The ultraview universal di-amino-benzidine detection kit (Zhongshan Golden Bridge Co., Beijing, China) was used for reaction visualisation. True positive and negative controls were used for histochemical and IHC stains. All IHC antibodies were ready-to-use solutions and were provided by Zhongshan Golden Bridge Co., Beijing, China. Slides were examined under a light microscope. In-situ hybridisation (ISH) was used for the detections of viral RNA in hepatic and lymphoid tissues. SARS-CoV-2 RNA probe, control probes and RNAscope 2.5HD detection kit for formalin-fixed and paraffin-embedded tissues were all provided by the Advanced Cell Diagnostics (USA). All hybridisation processes were performed according to the manufacturer's guidelines in pathology laboratory of Zhongshan Golden Bridge Co. (Beijing, China).
Table 1 Brief clinical information of patients with confirmed COVID-19

\begin{tabular}{|c|c|c|c|}
\hline & Patient 1 & Patient 2 & Patient 3 \\
\hline Age (years) & 94 & 65 & 75 \\
\hline Sex & Female & Male & Female \\
\hline \multirow[t]{5}{*}{ Baseline diseases } & Hypertension & No record diseases & Old MI \\
\hline & CHD & & CHD \\
\hline & CHF & & Hyperlipidaemia \\
\hline & & & Hypertension \\
\hline & & & T2-DM \\
\hline Chest CT & Patchy shadows & $\begin{array}{l}\text { Ground-glass and } \\
\text { plaque shadows }\end{array}$ & Patchy shadows \\
\hline \multicolumn{4}{|l|}{ Laboratory } \\
\hline $\begin{array}{l}\text { Elevated } \\
\text { neutrophil level }\end{array}$ & Yes & Yes & Yes \\
\hline $\begin{array}{l}\text { Low lymphocyte } \\
\text { level }\end{array}$ & Yes & Yes & Yes \\
\hline $\begin{array}{l}\text { Elevated CRP } \\
\text { level }\end{array}$ & Yes & Yes & Yes \\
\hline $\begin{array}{l}\text { Elevated PCT } \\
\text { level }\end{array}$ & Yes & Yes & Yes \\
\hline Elevated CK level & No & No & Yes \\
\hline $\begin{array}{l}\text { Elevated cTnl } \\
\text { level }\end{array}$ & No & No & Yes \\
\hline $\begin{array}{l}\text { Elevated ALT } \\
\text { level }\end{array}$ & No & No & Yes \\
\hline $\begin{array}{l}\text { Elevated AST } \\
\text { level }\end{array}$ & No & No & Yes \\
\hline $\begin{array}{l}\text { Elevated bilirubin } \\
\text { level }\end{array}$ & No & No & Yes \\
\hline \multirow[t]{4}{*}{ Clinical diagnosis } & NCP & NCP & NCP \\
\hline & ACS & ARDS & AMI \\
\hline & CE & Sepsis & AHF \\
\hline & AHF & & Liver dysfunction \\
\hline \multirow[t]{2}{*}{ Organ biopsy } & Lung & Lung & Heart \\
\hline & & Lymph node & Liver \\
\hline
\end{tabular}

ACS, acute coronary syndromes; AHF, acute heart failure; ALT, alanine aminotransferase; $\mathrm{AMI}$, acute myocardial infarction; ARDS, acute respiratory distress syndrome; $\mathrm{AST}$, aspartate aminotransferase; $\mathrm{CE}$, pericardial effusion; $\mathrm{CHD}$, coronary heart disease; $\mathrm{CHF}$, chronic cardiac failure; $\mathrm{CK}$, creatine kinase; $\mathrm{CRP}, \mathrm{C}$ reactive protein; CTnl, cardiac troponin-l; MI, myocardial infarction; NCP, novel coronavirus pneumonia; PCT, procalcitonin; T2-DM, type 2 diabetes mellitus.

\section{RESULTS}

\section{Histology of pulmonary and paratracheal lymphoid tissue}

In patient 1 , the total length of pulmonary tissue obtained was $40 \mathrm{~mm}$. On histological examination, some alveoli were found to be collapsed (figure 1A), and the alveolar spaces were filled with proteinaceous exudates with varying degrees of hyaline membrane (figure 1B). The pneumocytes lining the alveoli were exfoliated. The alveolar septa was widened and was infiltrated by the inflammatory cells including lymphocytes, phagocytes and a small number of neutrophils (figure 1C). These histological findings were found to be consistent with the acute phase of diffuse alveolar damage (DAD), but no evidence of organisation was found in this patient. In addition, we obtained a bronchial tissue sample, which revealed a cluster of submucosal glands. Additionally, few lymphocytes were noticed in the submucosal stroma (figure 1D), but none of the features suggestive of glandular damage could be appreciated.

In patient 2, we obtained six cores of pulmonary tissue with the total length of $38 \mathrm{~mm}$. On histological examination, it revealed fibrinous exudates, occupying the alveolar spaces, 


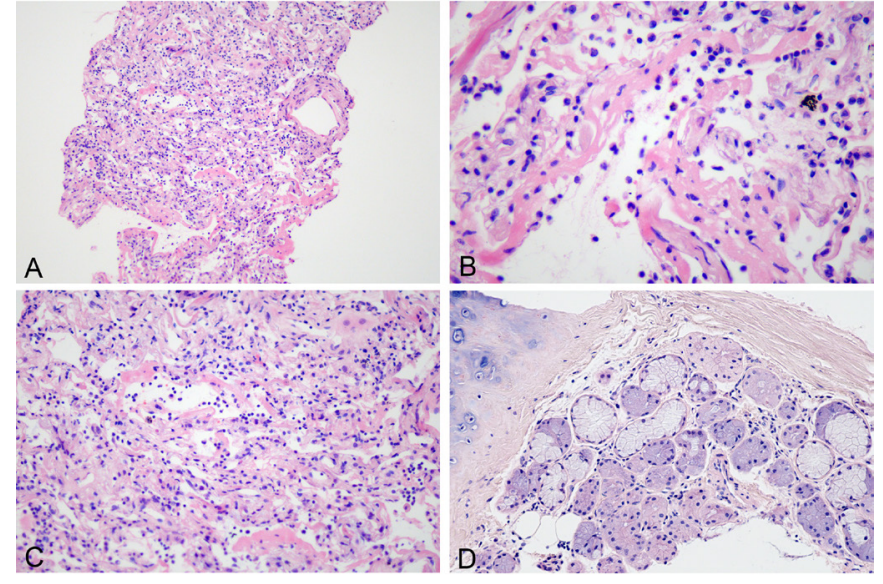

Figure 1 Histological changes of exudative phase of COVID-19 pneumonia seen in patient 1. (A) Focal alveolar collapse (H\&E 10X). (B) Hyaline membrane formation (H\&E 40x). (C) Widened alveolar septa and lymphocytic infiltration (H\&E 20x). (D) Bronchial submucosal glands with a few lymphocytes in the stroma (H\&E 20x).

intermixed with numerous neutrophils, phagocytes and cellular fragments (figure 2A). Hyperplasia of type II pneumocytes was observed (figure 2B), with the presence of a few large cells having suspicious viral inclusions (small vacuoles or perinuclear halos) in their cytoplasm (figure 2C). Alveolar walls were found to be extensively destroyed, and diffusely infiltrated by inflammatory cells, with concentrated inflammatory exudate filling the airspaces (figure 2D). While some of the alveolar spaces had hyaline membrane (figure $2 \mathrm{E}$ ), the squamous metaplasia was appreciated in others (figure $2 \mathrm{~F}$ ). The alveolar septum appeared widened due to the presence of congested pulmonary capillaries
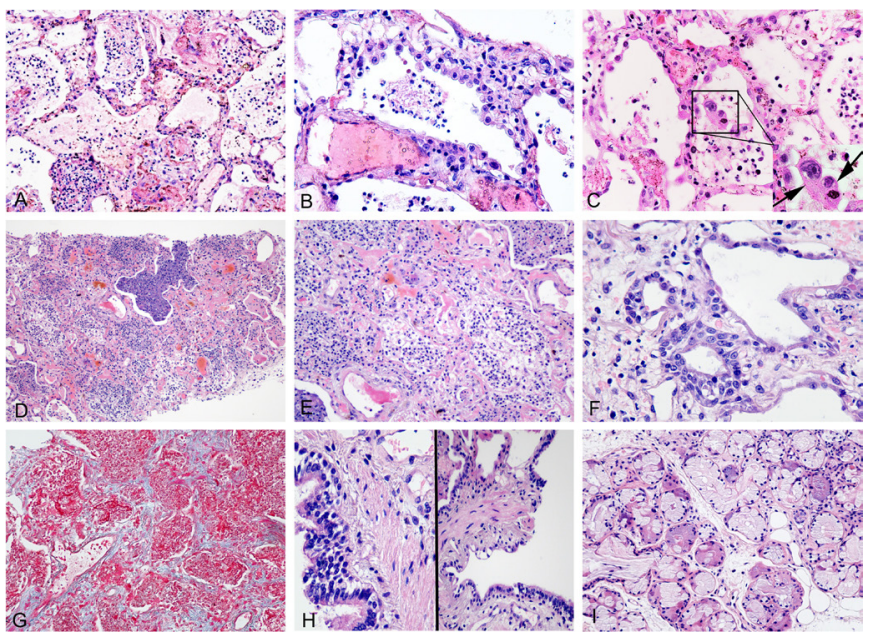

Figure 2 Histological changes of organising phase of COVID-19 pneumonia seen in patient 2. (A) Fibrinous exudates in alveoli with admixed inflammatory cells and cell fragments (H\&E 20x). (B) Hyperplastic pneumocytes (H\&E 40x). (C) Exfoliated pneumocytes in alveolar spaces, some with suspected viral inclusions (arrow) (H\&E 40x). (D) Organising diffuse alveolar damage with concentrated inflammatory exudate filling the airspaces (H\&E 10x). (E) Residual hyaline membrane in the organising background (H\&E 20x). (F) Squamous metaplasia of alveolar spaces (H\&E 40x). (G) Interstitial oedema and early fibrosis (Masson trichrome stain 20x). (H) A few inflammatory cells around the bronchioles (H\&E 40X). (I) A few lymphocytes seen in the stroma of bronchial submucosal glands (H\&E 20x).
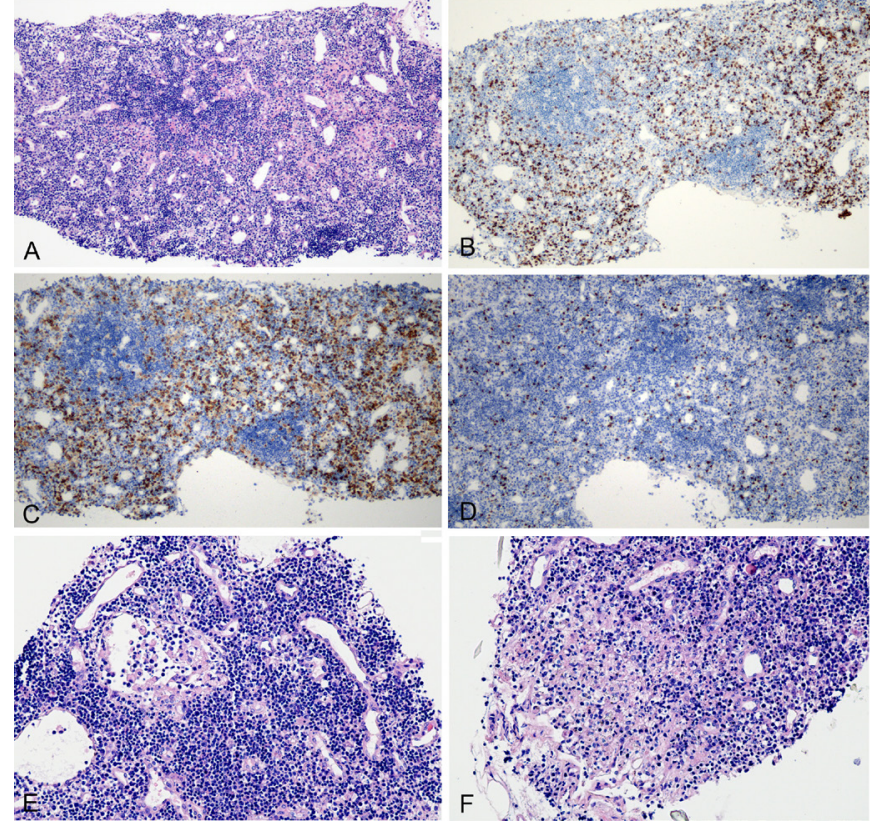

Figure 3 Histological changes of intrathoracic lymph node. (A) Primary lymphoid follicles with slightly widened interfollicular zone (H\&E 10x). (B) CD3-positive lymphocytes (immunohistochemical (IHC) stain 10x). (C) CD4-positive stain lymphocytes (IHC stain, 10x). (D) CD8-positive stain lymphocytes (IHC stain, 10x). (E) Lymphatic sinus dilation and vascular endothelial hyperplasia (H\&E 20x). (F) Focal necrosis (H\&E 20x).

and proliferating fibroblasts (figure 2G). The observed histological changes were suggestive of an organising phase of DAD complicated by bacterial pneumonia.

There was a presence of few bronchioles in the biopsy samples, which revealed an occasional vacuolar degeneration of epithelial cells and an absence of significant inflammation around the bronchioles (figure $2 \mathrm{H}$ ). However, there was a presence of a cluster of submucosal glands, which revealed a slightly increased mucous secretion in the glandular lumen. Similar to the findings observed in patient 1 , only a few lymphocytes were noticed to infiltrate the stroma, but there were no features suggestive of glandular damage (figure 2I).

One tissue core was found to consist of lymphoid tissue, presumably from a paratracheal lymph node. The light microscopic examination revealed the presence of primary lymphoid follicles, which was confirmed by immunohistochemistry demonstrating CD21(+) and CD10(-) stains (data not shown). The IHC stained sections revealed slightly widened interfollicular zones (figure $3 \mathrm{~A}$ ), with scattered CD3(+) $\mathrm{T}$ lymphocytes (figure $3 \mathrm{~B})$, and a slightly increased ratio of $\mathrm{CD} 4(+) / \mathrm{CD} 8(+)$ cells (figure 3C and D). Other histological findings included the presence of lymphatic sinus and vascular endothelial hyperplasia (figure 3E), focal necrosis (figure 3F), cellular degeneration and nuclear fragmentation. However, ISH did not reveal the presence of SARS-CoV-2 RNAs in the lymphocytes.

\section{Histology of cardiac and hepatic tissue}

The total length of cardiac tissue obtained was $15 \mathrm{~mm}$. Histological examination revealed features of old MI with hypertrophic myocytes and fatty infiltration (figure 4A), focal area with ischaemic degeneration of myocytes and nuclear pyknosis (figure 4B), and interstitial oedema and fibrosis (figure 4C). However, the infiltration of lymphocytes (data not shown, 

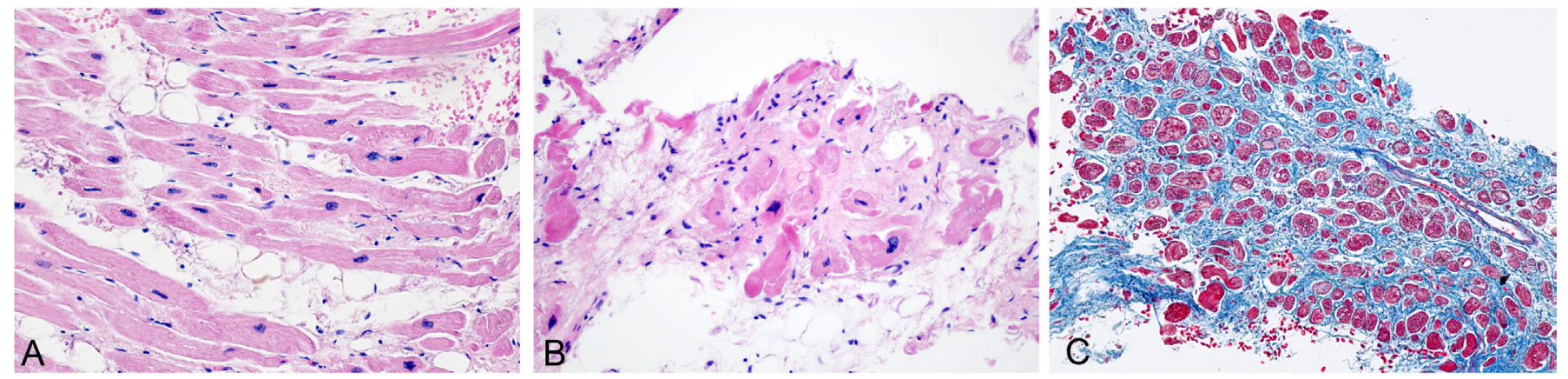

Figure 4 Histological changes of myocardium with old myocardial infarction. (A) Myocyte hypertrophy and fatty infiltration (H\&E 20x). (B) Focal ischaemic necrosis (H\&E 10x). (C) Interstitial fibrosis (Masson trichrome stain 10x).

immunohistochemistry showing negative LCA stain) or neutrophils could not be appreciated.

Additionally, six cores of hepatic tissue were obtained, with an aggregate length of $30 \mathrm{~mm}$. Histologically, three cores revealed large areas of coagulative necrosis, mainly around the central veins (zone 3). In areas with greater severity, coagulative necrosis involved the entire lobules (figure 5A). Around the areas with coagulative necrosis, microvesicular steatosis was observed in viable hepatocytes, but there was no significant inflammatory cell infiltrate (figure 5B). These findings can be considered to represent an ischaemic injury. The other three cores were biopsied from different areas of the liver and revealed an inflammation around the central vein (figure 5C) and small foci of confluent necrosis with mild mononuclear cell infiltrates (figure 5D). Other histological features involved activated histiocytes, occasional apoptotic hepatocytes, mild microvesicular steatosis and canalicular cholestasis (figure 5E). ISH did not reveal the SARS-CoV-2 RNAs in hepatocytes and cholangiocytes. Based on the available clinical history, these findings were suggestive of non-specific lobular hepatitis which might be drug induced.

Multiorgan pathological alterations and clinicopathological correlation are summarised in table 2.

\section{DISCUSSION}

The histopathological findings observed in pulmonary tissue, biopsied from two patients with severe SARS-CoV2 pneumonia, reported in this paper, revealed the characteristics of DAD, with both early (exudation stage) and end stage (organisation stage).

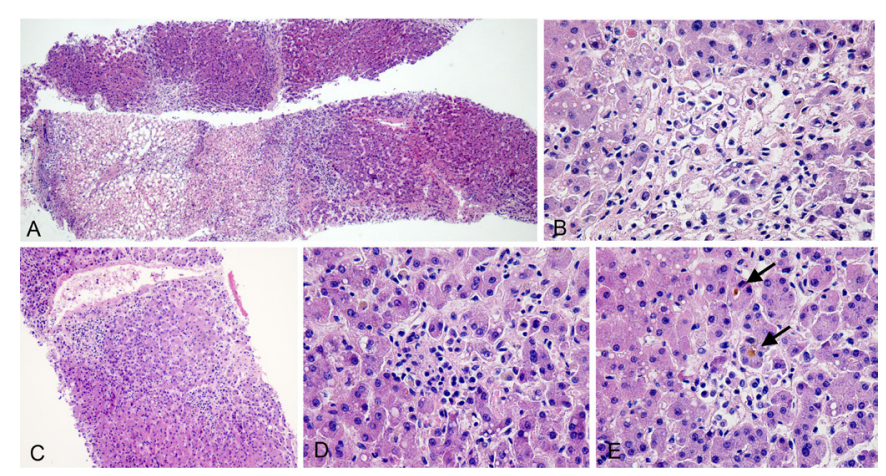

Figure 5 Histological changes of the liver. (A) Large areas of coagulative necrosis (H\&E 4×). (B) Focal coagulative necrosis without obvious inflammation (H\&E 40x). (C) Inflammation around a central vein (H\&E 10x). (D) Small focus of confluent necrosis with mild mononuclear cell infiltration (H\&E 40x). (E) Canalicular cholestasis (arrow; H\&E 40x).
The DAD is a descriptive diagnosis for a series of histopathological changes following acute pulmonary injury. It manifests, clinically, in most of the patients, as an ARDS. The histological findings of the pulmonary tissue biopsied from patients 1 are similar to those recently described by Tian $e t ~ a l .{ }^{4}$ In that report, two patients underwent lobectomies for lung adenocarcinoma, but, soon after the operation, were accidentally found to have SARS-CoV-2 infection. Histological examination of non-neoplastic pulmonary tissues revealed an early-stage changes of $\mathrm{CoV}$ pneumonia. The early-stage features of DAD included oedema, exudation and hyaline membrane formation (not reported in Tian's report, but observed in two patients of this report). Exudation and hyaline membrane formation can result in blood-air-barrier injury, thereby, hampering the oxygen diffusion in the alveolar spaces. Simultaneously, hypoxia can also result in constriction of pulmonary arteriole, increased pulmonary vascular resistance and hypertension. Patient 1 , of this report, was an elderly woman with various comorbidities including CHD and chronic cardiac insufficiency. Although the histological examination of pulmonary tissue revealed an early stage of DAD, it may lead to myocardial hypoxia and pulmonary hypertension. This is further supported by the fact that the patient presented with an acute exacerbation, a clinical process of chronic cardiac insufficiency, and malignant arrhythmia resulting because of the ischaemic cardiomyopathy.

Apart from the above-mentioned features, the advanced or end stage of DAD is characterised by inflammatory cell infiltrates, pneumocyte hyperplasia and pulmonary fibrosis, ${ }^{5}$ as observed in patient 2 of this report. Moreover, few suspicious viral inclusions with small vacuoles or perinuclear halos were observed in the alveolar epithelial cells. Recently, Yao et al visualised the pulmonary tissue, from an autopsy specimen of patient with COVID19 , under the electron microscope and found $\mathrm{CoV}$ particles in cytoplasm. ${ }^{6}$ In addition, during hospitalisation, patient 2 developed progressive dyspnoea and thus required mechanical ventilation. However, 24 hours later, laboratory findings suggested bacteraemia (including increased neutrophil count and PCT levels). This was further supported by the presence of complicated bacterial pneumonia in the postmortem biopsy. Finally, after 10 days of mechanical ventilation, the patient succumbed due to septic shock and multiorgan failure. However, we could not find changes suggestive of significant bronchiolitis which is commonly associated with ventilator-associated pneumonia. Thus, we can conclude that acute DAD may favour the development of bacterial pneumonia.

SARS-CoV-2 and two other highly pathogenic CoVs, SARS-CoV and MERS-CoV, have similar clinical manifestations ranging from asymptomatic infection to severe disease. 
Table 2 Multiorgan histopathological alterations and clinicopathological correlation

\begin{tabular}{|c|c|c|c|c|c|}
\hline & \multicolumn{2}{|l|}{ Pulmonary tissue } & \multirow{2}{*}{$\begin{array}{l}\text { Lymphoid tissue } \\
\text { (patient 2) }\end{array}$} & \multirow{2}{*}{$\begin{array}{l}\text { Cardiac tissue } \\
\text { (patient 3) }\end{array}$} & \multirow{2}{*}{$\begin{array}{l}\text { Hepatic tissue } \\
\text { (patient 3) }\end{array}$} \\
\hline & Patient 1 & Patient 2 & & & \\
\hline $\begin{array}{l}\text { Histopathological } \\
\text { alterations }\end{array}$ & $\begin{array}{l}\text { Alveolar collapse, } \\
\text { exudates, hyaline } \\
\text { membrane, } \\
\text { widened alveolar septa } \\
\text { and } \\
\text { few lymphocytic infiltrates }\end{array}$ & $\begin{array}{l}\text { Pneumocyte hyperplasia, } \\
\text { early fibrosis, } \\
\text { residual hyaline membrane, } \\
\text { suspected viral inclusions and } \\
\text { neutrophilic infiltrates }\end{array}$ & $\begin{array}{l}\text { Primary lymphoid follicles, } \\
\text { scattered T lymphocytes, } \\
\text { focal necrosis, } \\
\text { nuclear fragmentation and } \\
\text { negative viral RNA }\end{array}$ & $\begin{array}{l}\text { Hypertrophic myocytes, } \\
\text { fatty infiltration, } \\
\text { nuclear pyknosis, } \\
\text { interstitial oedema, and } \\
\text { fibrosis }\end{array}$ & $\begin{array}{l}\text { Coagulative necrosis, } \\
\text { microvesicular steatosis, } \\
\text { apoptosis, } \\
\text { canalicular cholestasis and } \\
\text { negative viral RNA }\end{array}$ \\
\hline Pathological diagnosis & Early DAD & $\begin{array}{l}\text { Late DAD combined with bacterial } \\
\text { pneumonia }\end{array}$ & $\begin{array}{l}\text { Non-specific acute } \\
\text { lymphadenitis }\end{array}$ & OMl & $\begin{array}{l}\text { Ischaemic hepatic injury } \\
\text { with mild lobular hepatitis }\end{array}$ \\
\hline $\begin{array}{l}\text { Clinicopathological } \\
\text { correlation }\end{array}$ & $\begin{array}{l}\text { DAD results in chest } \\
\text { tightness, dry cough } \\
\text { and decline in } \mathrm{SaO}_{2} \text { and } \\
\text { exudates caused the } \\
\text { chest } \mathrm{CT} \text { to show patchy } \\
\text { shadows. }\end{array}$ & $\begin{array}{l}\text { DAD causes extensive destruction } \\
\text { of alveolar epithelium and } \\
\text { increases the chance of secondary } \\
\text { bacterial infection. Pulmonary } \\
\text { organisation caused the chest CT } \\
\text { to show ground-glass and plaque } \\
\text { shadows. }\end{array}$ & $\begin{array}{l}\text { Lymphocytic degeneration } \\
\text { of lymph nodes leading to } \\
\text { a decrease in peripheral } \\
\text { lymphocyte count. }\end{array}$ & $\begin{array}{l}\text { Acute exacerbation of } \mathrm{OMl} \text {; } \\
\text { and rise in serum levels of } \\
\text { creatine kinase. }\end{array}$ & $\begin{array}{l}\text { Hepatocyte necrosis caused } \\
\text { by hepatic ischaemia and } \\
\text { lobular hepatitis may caused } \\
\text { by drug-induced hepatic } \\
\text { injury. }\end{array}$ \\
\hline
\end{tabular}

DAD, diffuse alveolar damage; OMI, old myocardial infarction.

Moreover, SARS-CoV-2 shares a high genetic homology with SARS-CoV. ${ }^{78}$ Our findings further demonstrate that there are similarities in pulmonary pathological changes caused by three different types of CoVs, including exudative DAD with hyaline membrane formation, pulmonary oedema, type II pneumocyte hyperplasia and interstitial lymphocytic infiltration. ${ }^{9-12}$ However, in contrast to the autopsy findings of patients with MERS and SARS, as discussed above, we did not find any significant bronchial or bronchiolar lesions, such as bronchiolitis or submucosal gland necrosis. ${ }^{911}$ Although our histological observations are limited to the core biopsy specimens, we hypothesised that the main pathogenic target of SARS-CoV-2 might be the alveolar epithelium rather than the bronchial/bronchiolar mucosa. Our findings may partly explain the reason why majority of the patients (72.2\%) present with dry cough, but only few have sore throat. ${ }^{13}$

The histological findings in hepatic, cardiac and lymphoid tissue suggest that non-virus damages to extrapulmonary tissue are possible. Specimens of hepatic tissue revealed mild lobular hepatitis, in addition to the presence of more obvious ischaemic injury. A recent autopsy study by Dominic et al reported a high incidence of deep venous thrombosis in patients with COVID19. ${ }^{14}$ So, we can speculate that the hepatic ischaemic injury may indicate the presence of hepatic vascular thrombosis. However, cholestasis and lobular hepatitis are more common in virus hepatitis and drug-induced liver injury rather than ischaemic damage. ${ }^{15}$ Combination of clinical process and the negative ISH findings (SARS-CoV-2) made us speculate that the cholestasis and lobular hepatitis were caused by drug-induced hepatic injury. This is further supported by the fact that the elevated transaminase levels appeared after initiating the treatment, and clinicians admitted that a combination of high-dose hepatotoxic drugs (including but not limited to ibuprofen, tolvaptan, atorvastatin and calcium) was used during the treatment.

In the early stage of epidemic in China, clinicians noticed that COVID-19 could significantly affect the cardiac function, ${ }^{16}$ and this was confirmed by various clinical reports. ${ }^{17}$ Thus, SARSCoV-2-associated myocarditis was suspected by the clinicians. However, histopathological examination did not reveal significant inflammatory cells, and the features observed in cardiomyocytes were suggestive of old ischaemic myocardial damage. Similar findings were reported in the recent autopsy examination in the US $(n=2)$ and Austria $(n=10)$. Moreover, no evidence of acute viral myocarditis was found either histologically or aetiologically. ${ }^{18} 19$

Similar to our study, Dominic et al evaluated some patients with viraemia and used reverse-transcriptase PCR to amplify the SARS-CoV-2 from extrapulmonary organs (such as liver). ${ }^{14}$ However, in our study, virus was not detected in hepatocytes, cholangiocytes and lymphocytes (of lymphoid tissue) by ISH stains. Thus, in our opinion, we cannot rule out that the positive virus amplified, by Dominic et al, originated from the intrahepatic blood cells. The viral sepsis hypotheses proposed by Li et al may partly explain these extrapulmonary histological changes, ${ }^{20}$ but further scientific research is required.

In summary, we described the histopathological alterations in pulmonary, hepatic, cardiac and lymphoid tissues obtained through percutaneous core biopsies in three patients with COVID-19. DAD was the main histological feature in the patients with confirmed COVID-19, and may favour the development of secondary bacterial pneumonia, especially in the patients with severe COVID-19 who received mechanical ventilation. Other extrapulmonary organs such as heart, liver and lymph nodes did not reveal any virus-specific changes. Moreover, in hospitalised patients, with disease progression, elevated liver enzymes may be attributed to drug toxicity or ischaemic injury. The findings, in this report, caution the pathologists, assessing the samples from patient with confirmed COVID-19, that they should not mistakenly attribute all the histological features to CoV infection. The health status and clinical process of the concerned

\section{Take home messages}

- Diffuse alveolar damage (DAD) was the main histopathological feature of severe acute respiratory syndrome coronavirus 2 pneumonia, and the severe DAD favours the development of bacterial pneumonia.

- Extrapulmonary tissues (such as cardiac, hepatic and lymphoid) did not reveal any virus-specific changes, but were affected by multiple factors.

- For confirmed patient with COVID-19, histological findings should be combined with the clinical features to analyse the pathogenesis.

- The clinicians should pay attention to the potentially injurious and correctable causes. 
patient should also be taken into consideration. Moreover, the clinicians should pay attention to the potentially injurious and correctable causes.

\section{Handling editor Dhirendra Govender.}

Acknowledgements The authors would like to thank the patients and their families for the support provided during the conduct of the study. Authors would also like to thank Hanlin Wang, Professor, Department of Pathology, UCLA, for the expert revisions and suggestions.

Contributors X-XW conceived the study. All authors acquired, analysed and interpreted data. X-xW and F-dL drafted the manuscript. All authors revised the manuscript and approved the final version.

Funding The authors have not declared a specific grant for this research from any funding agency in the public, commercial or not-for-profit sectors.

Disclaimer This abstract has been translated and adapted from the original English-language content. Translated content is provided on an "as is" basis. Translation accuracy or reliability is not guaranteed or implied. BMJ is not responsible for any errors and omissions arising from translation to the fullest extent permitted by law, BMJ shall not incur any liability, including without limitation, liability for damages, arising from the translated text.

Competing interests None declared.

Patient consent for publication Not required.

Ethics approval This study complies with the regulations issued by the National Health Commission of China and was approved by the Ethics Committee of Beijing Youan Hospital, Capital Medical University, Beijing, China.

Provenance and peer review Not commissioned; externally peer reviewed.

Data availability statement Data are available in a public, open access repository. Data are available upon reasonable request.

Open access This is an open access article distributed in accordance with the Creative Commons Attribution Non Commercial (CC BY-NC 4.0) license, which permits others to distribute, remix, adapt, build upon this work non-commercially, and license their derivative works on different terms, provided the original work is properly cited, appropriate credit is given, any changes made indicated, and the use is non-commercial. See: http://creativecommons.org/licenses/by-nc/4.0/.

\section{ORCID iD}

Xin-xin Wang http://orcid.org/0000-0001-9073-9017

\section{REFERENCES}

1 The website of who novel coronavirus (COVID-19) situation daily update. Available: https://www.who.int/emergencies/diseases/novel-coronavirus-2019/

2 Guan W-J, Ni Z-Y, Hu Y, et al. Clinical characteristics of coronavirus disease 2019 in China. N Engl J Med 2020;382:1708-20.

3 National Health Commission of the People's Republic of China. Diagnosis and treatment guidelines of new coronavirus pneumonia. 5th edn, 2020.

4 Tian S, Hu W, Niu L, et al. Pulmonary pathology of early-phase 2019 novel coronavirus (COVID-19) pneumonia in two patients with lung cancer. J Thorac Oncol 2020;15:700-4.

5 Anna-Luise A, Katzenstein MD. Diagnostic atlas of non-neoplastic long disease: a practical guide for surgical pathologists. NewYork: Springer Press, 2016.

6 Yao X-H, He Z-C, Li T-Y, et al. Pathological evidence for residual SARS-CoV-2 in pulmonary tissues of a ready-for-discharge patient. Cell Res 2020;30:541-3.

7 Zhou P, Yang X-L, Wang X-G, et al. A pneumonia outbreak associated with a new coronavirus of probable bat origin. Nature 2020;579:270-3.

8 Wu F, Zhao S, Yu B, et al. Author correction: a new coronavirus associated with human respiratory disease in China. Nature 2020;580:E7.

9 Nicholls JM, Poon LLM, Lee KC, et al. Lung pathology of fatal severe acute respiratory syndrome. Lancet 2003;361:1773-8.

10 Ding $\mathrm{Y}$, Wang $\mathrm{H}$, Shen $\mathrm{H}$, et al. The clinical pathology of severe acute respiratory syndrome (SARS): a report from China. J Pathol 2003;200:282-9.

$11 \mathrm{Ng} \mathrm{DL}$, Al Hosani F, Keating MK, et al. Clinicopathologic, immunohistochemical, and ultrastructural findings of a fatal case of middle East respiratory syndrome coronavirus infection in the United Arab Emirates, April 2014. Am J Pathol 2016;186:652-8.

12 Alsaad KO, Hajeer AH, Al Balwi M, et al. Histopathology of Middle East respiratory syndrome coronovirus (MERS-CoV) infection - clinicopathological and ultrastructural study. Histopathology 2018;72:516-24.

13 Sun P, Qie S, Liu Z, et al. Clinical characteristics of hospitalized patients with SARSCoV-2 infection: a single arm meta-analysis. J Med Virol 2020;92:612-7.

14 Wichmann D, Sperhake J-P, Lütgehetmann M, et al. Autopsy findings and venous thromboembolism in patients with COVID-19. Ann Intern Med 2020. doi:10.7326/ M20-2003. [Epub ahead of print: 06 May 2020].

15 Lefkowitch JH. Scheuer's liver biopsy interpretation. Singapore: Elsevier Pet Ltd, 2015.

16 Huang C, Wang Y, Li X, et al. Clinical features of patients infected with 2019 novel coronavirus in Wuhan, China. Lancet 2020;395:497-506.

17 Bansal M. Cardiovascular disease and COVID-19. Diabetes Metab Syndr 2020;14:247-50.

18 Barton LM, Duval EJ, Stroberg E, et al. COVID-19 autopsies, Oklahoma, USA. Am J Clin Pathol 2020;153:725-33.

19 Lax SF, Skok K, Zechner P, et al. Pulmonary arterial thrombosis in COVID-19 with fatal outcome: results from a prospective, single-center, clinicopathologic case series. Ann Intern Med 2020. doi:10.7326/M20-2566. [Epub ahead of print: 14 May 2020].

20 Li H, Liu L, Zhang D, et al. SARS-CoV-2 and viral sepsis: observations and hypotheses. Lancet 2020;395:1517-20. 